\title{
Algunos aspectos del teatro de TEMA INDÍGENA EN COLOMBIA*
}

\author{
SOME ASPECTS OF INDIGENOUS THEME THEATER IN \\ Colombia
}

Ernesto Mächler Tobar ${ }^{1}$

\footnotetext{
Conferencia preparada para la Maestría en Literatura de la Universidad de Antioquia, realizada en dicha institución el 6 de marzo de 2018 .

Cómo citar esta conferencia: Mächler Tobar, E. (2019). Algunos aspectos del teatro de tema indígena en Colombia. Estudios de Literatura Colombiana 44, pp. 167-177. DOI: $\quad$ https://doi.org/10.17533/udea.elc. $\underline{\text { n44a10 }}$

ernesto.machler@u-picardie.fr Universidad de Picardie Jules Verne CEHA-Centre d'Études Hispaniques d'Amiens, France

Recibido: 15.08 .2018

Aprobado: 01.10.2018
}

Copyright: $@ 2019$ EstudiosdeLiteratura Colombiana Este es un artículo de acceso abierto distribuido bajo los términos de la Licencia Creative Commons AtribuciónNo comercial - Compartir igual 4.0 Internacional

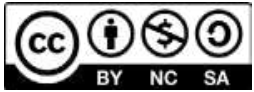

En esta presentación informal quiero compartirles mi recorrido como investigador en el teatro de temática indígena en Colombia. Si mi tesis de grado analizaba la presencia del indio en nuestra novela, ahora me intriga la dramaturgia donde un personaje importante es indígena o cuyo argumento está en relación con su mundo; he recopilado unos 200 textos, muchos inéditos. Parte de los resultados de la investigación ha sido publicada por la Universidad de Antioquia, y parte en Francia y Alemania; este extenso work in progress se concretizará en el futuro como ensayo. Escribe Manuel Scorza: "No lo veían porque no lo querían ver. Era invisible como invisibles eran todos los reclamos, los abusos, las quejas [...]. ¡Sería invisible! [...] ¡Sería invisible para todos los hacendados y vigilantes del mundo, y transparente, inaprensible, intocable, invulnerable, prepararía una magna sublevación!". Esto sintetiza la presencia del indígena en nuestro teatro, o mejor la invisibilidad a la que ha sido condenado. Lo observan con ojos distorsionados, lo imaginan como un otro al que no se acepta o comprende.

Nuestra problemática se remonta a 1580 , primera referencia de una representación en Colombia. Las colonias celebraban la llegada de representantes de la Corona con recepciones, cabalgatas, corridas de toros y obras de teatro amateur. Tal como sostiene Georges Balandier, "detrás de 
todas las formas de adecuación de la sociedad y de organización de poderes se halla, siempre presente, gobernante de la tras-escena, la "teatrocracia"". Teatro y poder avanzan justificándose mutuamente, y es fundamental entender esta relación dominante/dominado para comprender nuestra dramaturgia. ¿Puedo arriesgarme a hablar en pasado?

\section{Dramaturgia y momento histórico}

Elaboremos un succinto panorama de la dramaturgia con esta temática en Colombia. ¿Quiénes han escrito sobre el indígena? Presentemos siete períodos de los cuales no evocaremos todos los autores ni todas las obras: sería tedioso y ustedes pueden consultarlo en mis publicaciones. El primero corresponde a la época de la Colonia, con un teatro evangelizador centrado en asuntos religiosos, y con influencia del Siglo de Oro. Su función es enseñar el catolicismo a un pueblo que no comprende latín ni castellano, pero que integra con facilidad las representaciones de la liturgia: desaparecen los dioses indígenas y se impone el de los vencedores. Se destacan tres autores poco conocidos: Hernando de Ospina (c. 1605) con su Comedia de la guerra de los Pijaos; Fernando de Orbea (siglo XVII), con la Comedia nueva: la Conquista de Santa Fé de Bogotá; y Fray Felipe de Jesús (siglo XVIII), cuyo Poema cómico, dividido en dos partes y cinco Actos. Soñado en las costas del Darién (1789) es una justificación de la Conquista, con personajes como las Damas Nueva España, Lima y Santa Fe, mientras El Francés, El Inglés y El Escocés critican envidiosos las riquezas que adquiere España. Nueva España dice pretensiosa:

Toda estoy rica por dentro / y más brillo desde fuera. / [...] porque aunque los españoles / sean por su naturaleza / belicosos y guerreros, / sólo con razón pelean / y por eso en las conquistas / de las dos grandes Américas / les protegió con milagros / la divina omnipotencia.

Esta cita evidencia que, desde entonces, el indígena es hecho invisible. Luego leemos “en todo parecen brutos. / ¿Quita ese hombre de mi vista!”, lo que será el grito permanente del teatro que estamos considerando.

El segundo período marca el inicio de un verdadero teatro colombiano: la Independencia. Los dramaturgos son beligerantes, manejan la pluma y el sable con similar destreza centrándose en el combate, lo que aclara tanto su corta vida como lo inédito de sus obras. Sus personajes se encarnan confusos en variadas grafías. Destaquemos dramaturgos como José Fernández Madrid (1789-1830), conocido por sus piezas Atala (1822) y Guatimoc (1827), y el extraño Luis Vargas Tejada (1802-1829), que antes de enredarse en lides 
políticas contra el Libertador, apoyó su odio antiespañol con piezas como Aquimín (1819) y Witikindo (1820). Los hermanos Juan Francisco (18081875) y José Joaquín Ortíz Rojas (1814-1892), autor este último de Sulma (1834). Caso excepcional, Waldina Dávila de Ponce (1823-1900), cuya obra Zulma (1892), a pesar de la semejanza con el título de la obra de Ortíz Rojas, trata de una virreina del Perú. Y es vital Felipe Pérez (1834-1891), cuyas novelas y obras teatrales giran casi exclusivamente alrededor del mundo indígena, tal como Gonzalo Pizarro (1857).

El tercer período corresponde al Teatro Centenarista (1900-1930), que comprende gran cantidad de inéditos, lo que sorprende si tenemos en cuenta la calidad de los dramaturgos referenciados. El fugaz Alejandro Mesa Nicholls (1892-1920), autor de Lauro candente (1919), y el completo humanista que le otorgó al folclor plena validez como parte significativa de la cultura colombiana, Joaquín Piñeros Corpas (1915-1982), con obras como La muerte sonreída (1955), ejemplo de representación de una obra teatral al interior de su pieza. Caso excepcional es el de Antonio García Nossa (1912-1982), de quien se sabe que representaba con indios en los resguardos del Cauca obras pedagógicas como El resguardo. En este período vale la pena incluir a Hernando de Bengoechea (1889-1915) — sacrificado en las trincheras en defensa de Francia-, con su obra en francés Soratama (1922), escrita como libreto para una ópera de Guillermo Uribe Holguín, la cual nunca ha sido traducida.

El cuarto período ve la llegada de la radio y de sus innovaciones, que permitirán el acceso a muy variado y distante público. Al menos tres dramaturgos estrenan sus piezas en la Radiodifusora Nacional. Se inicia con la tragedia clásica La Gaitana (1937), de un propulsor del radioteatro, Oswaldo Díaz Díaz (1910-1967), transmitida en 1940. Luego, Luna de arena (1942), del poeta Arturo Camacho Ramírez (1910-1983), única obra de un dramaturgo recreada después por un autor no nacional: lo hará Ramón Vinyes y Cluet (1882-1952) en A orillas del mar Caribe (1943). El más radiofónico, sin embargo, es Luis Hernando Vargas Villamil (1916-2011), cuya obra La Gaitana (1959) está estructurada como serie de aventuras que se detienen en el momento crítico y dejan al oyente con las ansias de la continuación.

La quinta etapa, alrededor de los años setenta, asombra por su variedad y calidad: se inicia el fastuoso período denominado "Nuevo Teatro Colombiano", y se implementa la "Creación colectiva", propuesta 
en la que el diálogo entre escritor, actores y público genera una obra de coherente ideología. No solo cesan los intercambios con el exterior a causa de la violencia que asfixia al país, sino que varios autores se exilian debido a los vaivenes políticos; ello les permite intercambiar con otras técnicas y creadores internacionales. El más conocido de estos ensayistas y críticos es Enrique Buenaventura (1925-2003), de quien se destaca el importante trabajo asociado al Teatro Experimental de Cali. Sobresalen otros dramaturgos que harán escuela: Santiago García (1928), Luis Alberto García (1937), Fernando González Cajiao (1938-1997) y Carlos José Reyes Posada (1941), por ejemplo. En La tras-escena (1984), de Fernando Peñuela Ortíz (1948-2011), los indios están presentes, pero fuera del escenario: "¡Yo sin indios no estreno esta obra!", afirma el director. Seguimos con otra forma de la ausencia a pesar de la presencia. Notamos una creciente participación femenina: Rosario Montaña Cuéllar (1941), Nelly Domínguez Vázquez, Julia Rodríguez, Patricia Ariza (1946), de la que destacamos El viento y la ceniza (1986), y Beatriz Camargo Estrada (1946), quien con su Teatro Itinerante del Sol incursiona en la herencia de Eugenio Barba y su Teatro Antropológico. En Enigma (2004) afirma: "ya no queremos sus espejitos"; aborda así la posibilidad de evocar la historia desde el punto de vista de los vencidos y revaloriza el ancestro indígena. La obra ilustra el choque entre los mundos indígena y blanco, acelerado por la llegada de los antropólogos. Pasado y presente, mito y realidad se confunden:

Omawe, con un machete, de un golpe, crea motores fuera de borda, y bongos,
y techos de zinc... Y desborda el río, allá, donde el mundo se acaba... Vienen
hombres ahogados... Omawe los recoge, los pone a secar al lado del fuego. Se
tuestan... Con el machete, Omawe, los raspa. El que queda muy tostado, negro, es
africano, el que queda blanco, es el musiú. El que queda de buen color, tostadito...
es gente Yanomami.

La sexta etapa se traslapa con la anterior: en la segunda mitad del siglo $\mathrm{xx}$, ciertos autores que conocen las experiencias del trabajo colectivo deciden mantenerse al margen y firmar sus obras: marginalidad que no excluye su compromiso político. Los más significativos son Manuel Zapata Olivella (1920-2005), mejor conocido como novelista, Mario Cardona Osorio, inspirado por la mitología peruana, y el iconoclasta Henry Díaz Vargas (1948), que a la manera del Preciado rulfiano establece una permanente conversación sobre los indios entre personajes occisos: el Adelantado Sebastián de Belalcázar conversa con el Mariscal Jorge Robledo en Más allá de la ejecución (1984). 


\section{Situación actual: ¿un teatro más reivindicativo?}

Una renovación del teatro se impone para enfrentar los cambios de gusto del público, el inquietante éxito del banal café-teatro y la explosión de los medios de comunicación masiva; se requiere una dramaturgia más popular. Llegan propuestas innovadoras que hacen difícil olvidar el impacto del Teatro Antropológico y de la etnoescenología, del cultural performance, del teatro japonés Nô, de la danza Butoh, del teatro de la India y de Balí. Tanto ceremoniales como rituales indígenas retornan al escenario como nuevas formas de comunicación con el espectador. El humor brota como defensa ante la violencia del narcotráfico y el paramilitarismo. Julio Olaciregui (1951) indaga las relaciones que nos ligan con África, tanto en bailes como en costumbres, y se ancla como defensor del jagalismo, propuesta de reciclaje de elementos preexistentes, como el hombre icotea definido por Orlando Fals Borda. Inédita, Las novias de Barranca (1994) es muestra de ello: humor costeño y carnaval le permiten dinamitar el acartonado manual de la historia. De similar humor se sirve Juan Monsalve Pino (1951), profundo conocedor del teatro de la India y del teatro de sombras Wayang-Kulit, y prolífico creador con varias obras para público infantil como la divertida Fechorías de Felipillo el pillo con la Princesa Pataladesa (2001).

Juan Carlos Moyano Ortíz (1959) se inspira en los libros mayas para crear un teatro simbólico, como en Contrahuella. La senda de los ancestros (2004). Cerca del mundo ritual se hallan Luz Myriam Gutiérrez y Manuel Alberto Torres (Viento Teatro), quienes emplean el "lenguaje del mito" en Pamuri Mashe (Señor de la Semilla) y Sei-Nake Hába Sintu (Tierra Negra Madre Universal) (2007), basada en la cosmovisión Kogi. La Corporación Cultural Jayeechi y Bernardo Enrique Berbeo García (1963) reciben el premio noruego de creación Ibsen en 2017. Siguiendo consejos de los ancianos Wayúu producen obras como Jepira (Viaje al más allá), basada en la leyenda 'Ulepala' y en el cuento "Esa horrible costumbre de alejarme de ti", de Vicenta Siosi Pino; Wakuaipa (Nuestras costumbres, 1998), escrita en wayuunaiki y castellano, Amaygua (2004) y Kaulayawa (Juego de la Cabrita, 1993).

Este repertorio desborda el escenario clásico al apoderarse de espacios públicos citadinos: zonas de invasión, fábricas, plazas y cárceles, véase ágoras de confrontación democrática. Se aproxima a las antiguas fiestas populares recurriendo a músicos, elementos circenses, vestuarios con plumas y máscaras, zancos, antorchas y danzas. Recupera así el juego y su 
carácter lúdico; quizás ello explique que varias de las obras sean para un público infantil. Este teatro popular, afirma Roland Barthes, debe conllevar tres características: "un público de masa, un repertorio culto, una dramaturgia de avanzada", lo que le permite asegurar que "el teatro popular es el teatro que confía en el hombre". ¿Pedagogía o elemento vital para el cambio? En las sociedades occidentales, donde las expectativas sociales y la clase política generan desconfianza, donde tienden a desaparecer los códigos y las referencias heredadas, este teatro popular festivo de carácter ritual se acerca a la ceremonia religiosa o colectiva. ¿Estamos lejos del fenómeno catártico producido por un deporte popular como el fútbol?

\section{El idioma es parte del problema}

La lengua es eficaz, vehicula la cultura e influye en la percepción y conceptualización del mundo por una sociedad. Evidentemente, los idiomas ancestrales poseen esta capacidad y pretender que una lengua es superior a otra es chato etnocentrismo. Pero en nuestra problemática la escritura es privilegio de los vencedores: el blanco habla, escribe y actúa en lugar del indígena, expresándose en castellano e imponiendo su nomenclatura. Desaparece y oculta así al indígena de la historia, y se convierte en 'ventríloco', como propone Christian Gros. Esta política representa una cara de la dominación, y nos lleva a cuestionarnos, ¿en qué lengua habla entonces el indio personaje teatral? Existen varias obras prehispánicas parateatrales en lengua indígena; en el caso colombiano es significativo el Yuruparí, en lengua ñe'engatú. Después, la Real Cédula de Aranjuez (1770) impone el uso del castellano e impulsa la extinción de las otras lenguas; la Inquisición coadyuva al denominarlas dialectos bárbaros y diabólicos, temerosos de una contaminación de ideas. En su Poema Cómico, fray Felipe de Jesús, que menciona la orden real, hace afirmar al español que aunque los indígenas sean forzados a aprender la lengua del conquistador, no podrán comunicar con él, y "por eso en castellano no se les puede enseñar ninguna oración tampoco porque no saben hablar". Carlos Reyes en El Carnaval de la muerte alegre. Periplo de Balboa y Pedrarias (1991) hace que el encuentro entre Balboa y Anayansi implique tanto mestizaje como aprendizaje del castellano. La dificultad de comunicación será ideológica o filosófica, no idiomática.

La lengua perdida es otra posibilidad de dramaturgia y permite glosar sobre la desaparición de la solidaridad étnica. En La ira de Kinski (nosotros los blancos) (2012), Carlos Enrique Lozano Guerrero (1972) 
destaca esta pérdida de estructuración social: "Los indígenas [...] intentan hablar su lengua pero no saben cómo, han perdido el idioma que alguna vez les perteneció". Algo similar propone Ana María Vallejo de la Ossa (1965) en Oraciones (2010). La lengua se ha extraviado, por ello "Fray Miguel mira con amargura un rollo de papel que se deshace en sus manos, mientras pronuncia lentamente una lista de bellas palabras perdidas en su diccionario Otomí-Castellano, quemado por orden de la Inquisición". Cada vez que se ha traducido la Biblia, "una tras otra ardieron en candela las hojas de su escrito, y tal vez mejor así, practican ritos diabólicos, quién nos dice que sus palabras que tanto han nombrado al demonio puedan nombrar a Dios". Si bien los indígenas dominan la "lengua de cristiano", al acercarse la muerte, fray Miguel reconoce: "Y a ti es mi deseo llegar abrazándote Dios en lengua otomí". ¿Este idioma lo ha corrompido? Para Vallejo, importa más la transmisión del mensaje que la lengua escogida para hacerlo: todos los idiomas se valen.

La mayor parte de nuestros dramaturgos desconoce las lenguas indígenas, o estas ya están muertas o fuera de uso. Se recurre a ellas para nombrar personajes o dioses, para introducir algunas interjecciones o palabras sueltas en el texto, tal vez para incrementar la verosimilitud de la creación. Para paliar esa ignorancia, se acota en las didascálidas que hay que "tener mucha dignidad", "actuar majestuosamente", tener una "actitud hierática" y usar un recitativo poético. En ocasiones se ayudan de diccionarios, catecismos y otras fuentes, con el objetivo de aumentar la intensidad dramática. Santiago García ofrece con Nayra (2004) un caso particular, incluso en ausencia del indígena: la temática es aquella de la sanación en una maloca, visitada por personajes populares colombiananos. Propone el uso de lenguas como el inglés, el latín, los cantos de purificación africanos y el lenguaje de los sordomudos; entre las indígenas recurre al muisca, al tiana y al tupan guaraní. En muisca, por ejemplo, utiliza el inicio de la confesión: "Hycha gerca chianzin zi paba hata zona. Puinca quati bizha apquas. Uma bhosha pabi ahisica paba qui ma quenca shi pui nuca".

Otra ilustración la ofrecen Luz Myriam Gutiérrez y Manuel Alberto Torres, en Sei-Nake Hába Sintu (Tierra Negra Madre Universal). Los recitativos (voix-off) son en Kogi: "A-Kinga-Má-a-a [] Tashi Nyi, Kaba. Tashi Nyi, Kaba", o "Ahía- hé- hé- heee- ahia- hée. Mangüi, Bangüi, ShiMangüi, ahía-he, Sei-Nake, ahie". Una propuesta diferente efectúa Luz Peña Tovar (1961), cuya pieza Yajicuení [Hijos del Tigre de Espesura] (2005) 
evoca a fray Diego, salvado por Tayarí, indígena yajicuení, e incapaz de integrar su nueva existencia al considerar los dos mundos antagónicos. Peña poetiza los nombres de plantas y animales: la liana del yagé es "Trepadora de Soñar", la danta es "Cerdo de Salado" y el chamán, "Dador de luz". Los diálogos escritos en castellano deben ser escuchados en yajicueniate o en latín, lo que dificulta el montaje. Los sacerdotes imponen la lengua aunque comprendan el idioma indígena: "En la Casa de Dios, habla la Lengua de Dios", es decir, castellano.

El idioma puede ser sonido incomprehensible. En el radioteatro, las onomatopeyas, repeticiones rítmicas, ruidos y otros sonidos son utilizados con frecuencia, pero el sentido adquiere importancia secundaria. Otros dramaturgos optan por un guiño de ojos al emplear una lengua inventada pero comprensible para el espectador. Varios ejemplos se hallan en Colón perdido y desconocido por encantamientos de Balam Quitzé (1995), de Henry Díaz Vargas, donde humor y juegos de palabras dan lugar a una obra burlesca que cuestiona la historia, el idioma y las normas mismas. Curiosamente, los dramaturgos colombianos se sirven a menudo del latín o de alguna lengua latina, como italiano o francés; utilizan también inglés, alemán, vasco, y diferentes argots. El inglés corresponde a la presencia de estadounidenses entre los personajes: Carlos Parada (1942) se sirve del humor y en su parodia El Dorado colonizado (2009) emplea el inglés hispanizado del shou bísnes, Uisky, Yés, leidis and yentlemán. Los indígenas, por su parte, apenas cantan: "Pachanga...? Chirrinche... Pachanga...? Champeta...? Chingüa...? Changüa... Chupe...? Churupe... Cachimba...? Churumbela". Este discurso se apoya en su impacto fonético y privilegia la fuerza sonora del texto. El latín, como era de esperarse, está ligado a las ceremonias de religiosas, con frases asaz reconocibles como "In nomine Patris et Filiii et Spiritus Sancti". Canciones en gallego y vasco son frecuentes en $E l$ viento y la ceniza, de Patricia Ariza, donde una alienada canta para consolarse de las promesas incumplidas por el conquistador.

Hay que considerar la imperiosa necesidad de recurrir a una lengua o traductor. Fernando Peñuela Ortíz lo hace meollo de La tras-escena: los indios mal pagados están en huelga. Teatro dentro del teatro, asistimos a una comedia de Lope de Vega sobre Colón. El diálogo es de sordos, pues el traductor indígena contesta a las preguntas del director con respuestas llenas de poesía, pero ilógicas para un occidental: "No hay lugar para reposo, la tierra será lo que son los varones. Aún así en los caminos, ando recogiendo 
perlas...". Gracias al humor, parece considerar que la comunicación disminuye cuando los interlocutores hablan la misma lengua a niveles diferentes. El más recurrente traductor es Felipillo, lengua de Atahualpa y Pizarro. Santiago García, en Corre, corre Carigüeta (1982) presenta un Pizarro, único personaje no indio, emitiendo amenazas y pavorosos ruidos al mover los labios. Felipillo habla su "terrible lengua", su "lenguaje hostil", y lo traduce al paciente Atahualpa. El runasimi es poco utilizado aquí, lo esencial no es tanto la lengua misma como la necesidad imperiosa del traductor. Felipillo es tanto intérprete como verdugo de Atau Wallpan, tan traidor como lo han sido otros lenguas, Malintzin o Catalina, que ofrecen al invasor la llave para comprender al otro y favorecen la destrucción de sus propias etnias. Juan Monsalve vuelve a este traductor-traidor que busca sacar provecho en Fechorías de Felipillo el pillo con la Princesa Pataladesa, obra para público infantil. El recitante aclara que las palabras de Felipillo "tienen doble el sentido, como lengua de pillo engañado y engañoso nos muestra a todos cómo las palabras pueden servir para cualquier cosa". Atahualpa desconfía, pero no puede hacer otra cosa; Pizarro afirma por el contrario que "Tú, que sabes la lengua india, puedes traducir sin traicionar mi beneficio". En este diálogo lleva la ventaja quien domina los dos lados; ello no significa que siempre gana: los malentendidos culturales persisten y los prejuicios salen fortalecidos.

\section{¿Ciudadanos íntegros en el teatro?}

La utilización de la lengua indígena forma parte vital de las reivindicaciones étnicas y políticas y es indispensable para la supervivencia. Este derecho es reconocido por el Estatuto Nacional del Indígena (1979) que insiste en su preservación. La creación artística debe ser garantía de esta perpetuación e ineluctable reconocimiento de la indianidad. El uso de idiomas indígenas en literatura es frecuente en Canadá, Estados Unidos, México, Guatemala, Perú y Chile, por ejemplo. No obstante, el sistema dominante les pega etiqueta de 'etnopoesía', denominación a la cual nos oponemos de manera categórica. En Colombia hay ejemplos entre los Kamsá, Inga y Wayúu, sirviéndose del grafolecto castellano. En teatro, señalemos al grupo Inkayú (Putumayo), con actores ingas, kamsás, mintkas y wayúus, cuya obra más conocida es La Kukuawila (La devoradora vieja montés, 1992); y a Enrique Berbeo, que utiliza tanto el wayuunaiki como otros idiomas y se asocia con actores indígenas. 
Iniciábamos evocando un teatro evangelizador que intentaba cristianizar y enseñar el castellano al indígena, y veíamos la necesidad de los traductores; hemos llegado ahora al cambio esencial: el paso de la oratura a la literatura. El indígena es y debe constituírse en actor de su destino. La representación de obras escritas en lengua se facilita gracias a las técnicas que permiten el uso de subtítulos que desfilan. Si antes era imperiosa la presencia de un traductor que aclarara el discurso o se le cedía la necesaria explicación a otro personaje, ahora, entre otras causas por herencia del Teatro Antropológico, la representación de ritos y mitos no requiere de explicaciones. Los dramaturgos, directores y actores son indígenas, y es factible recurrir al uso de diálogos en sus lenguas. Los actuales escritores mestizos escriben sobre un indígena real, empleando un lenguaje menos retórico; el habla acartonada desaparece reemplazada por un discurso más cotidiano. Acotemos que de todos los autores estudiados, el único mencionado como indígena es Jacinto Albarracín (1876-19?), del cual solo se ha publicado Por el honor de una india (1916). Escribió también Furatena, pero el rastreo ha sido estéril como ocurre con su biografía.

Las lenguas y su grafía están maduras, y el dramaturgo indígena escribe en lengua vernácula demostrando que su cultura acepta el desafío de la creación literaria. Jean Duvignaud sostiene que el teatro es "una revuelta contra el orden establecido", y Pierre Bourdieu aclara que se requieren unas "condiciones sociales de aceptabilidad" para que esto se produzca. ¡La revuelta es aceptable! Excepto en casos aislados, el indígena como personaje de dramaturgia ya no es un decorado de fondo que muestra un idilio preludio del mestizaje; tampoco es otro explotado más en una confrontación imperialista por las materias primas, ni un compañero de lucha contra los terratenientes. Es otro ser humano agonista que indaga y plantea una nueva representación teatral de sí mismo y de sus angustias vitales. La temática sigue captando el interés de los artistas, comprometidos o no, interesados en la vasta comprensión y construcción del Estado-nación, lo que genera la esperanza, o al menos su utópica vislumbre, de ser aceptados como ciudadanos integrales.

Si comenzamos esta aproximación a algunos aspectos del teatro de tema indígena en Colombia utilizando como premisa la invisibilidad del indio, es porque no se le ha consagrado una encarnación importante, excepto en ínfimas excepciones, como Bochica, Sintana, La Gaitana o Atahualpa. ¿Memorizamos más la historia de la Conquista que la 
profundidad del personaje? Esta observación no quita validez literaria a esta dramaturgia. La temática no alcanza un porcentaje significativo dentro del teatro colombiano, si las cifras fueran criterio válido en literatura. No obstante, un representativo teatro indígena está aún por venir, y las obras aquí listadas representan magma en ebullición que labora un volcán para brotar; es un estado de pre-puesta en escena, o el de un diálogo similar al de los años setenta, buscando una creación colectiva nacional. Otro elemento que destacamos es la frecuencia con la cual los dramaturgos se inspiran en culturas indígenas extranjeras, especialmente de México, Perú y Guatemala. La mayoría de los autores presentan a un indígena del pasado, sobre el cual es posible elucubrar basándose en las parcializadas crónicas de la Conquista que trastocan la realidad americana del indígena. ¿Será el indio muerto el mejor indio para la dramaturgia? Queda por estudiar el empleo del genérico indios o la referencia a grupos étnicos concretos: ¿está tintada la utilización de ideología o implica una mirada peyorativa? ¿Se da cuando hay una recreación histórica definida? No es problema de cronologías de la pieza teatral, pues recordemos que Fernández Madrid escribe sobre los Tlascaltecas, etnia concreta, como también lo hace Zapata Olivella, mientras que otros dramaturgos como Peñuela recurren al genérico indios; en este último caso, bien es cierto que están en huelga. ¿Un uno plural, indefinido? Como ven, la posibilidad investigativa del indio en el teatro colombiano es amplia y prometedora. 